\title{
BMJ Open Seroprevalence of SARS-CoV-2 infection in healthcare workers in a large teaching hospital in the North West of England: a period prevalence survey
}

\author{
Robert John Shorten (D) , ${ }^{1,2}$ Shonagh Haslam, ${ }^{3}$ Margaret A Hurley, \\ Anthony Rowbottom, ${ }^{5}$ M Myers, ${ }^{3}$ Paul Wilkinson, ${ }^{1}$ David Orr ${ }^{1}$
}

To cite: Shorten RJ, Haslam S, Hurley MA, et al. Seroprevalence of SARS-CoV-2 infection in healthcare workers in a large teaching hospital in the North West of England: a period prevalence survey. BMJ Open 2021;11:e045384. doi:10.1136/ bmjopen-2020-045384

- Prepublication history and additional supplemental for this paper is available online. To view these files, please visit the journal online (http://dx.doi. org/10.1136/bmjopen-2020045384).

RJS and SH contributed equally.

Received 29 September 2020 Revised 06 February 2021 Accepted 22 February 2021

Check for updates

(C) Author(s) (or their employer(s)) 2021. Re-use permitted under CC BY-NC. No commercial re-use. See rights and permissions. Published by BMJ.

For numbered affiliations see end of article.

Correspondence to

Dr David Orr;

david.orr@|thtr.nhs.uk

\section{ABSTRACT}

Objectives Since its emergence in late 2019, SARSCoV-2 has caused a global pandemic that has significantly challenged healthcare systems. Healthcare workers have previously been shown to have experienced higher rates of infection than the general population. We aimed to assess the extent of infection in staff working in our healthcare setting.

Design A retrospective analysis of antibody results, compared with staff demographic data, and exposure to patients with COVID-19 infection.

Setting A large teaching hospital in the North West of England.

Participants 4474 staff in diverse clinical and non-patient facing roles who volunteered for SARS-CoV-2 antibody testing by the Roche Elecsys assay between 29 May and 4 July 2020.

Results Seroprevalence was $17.4 \%$. Higher rates were seen in Asian/Asian British (OR 1.61, 95\% Cl 1.27 to 2.04) and Black/Black British (OR 2.08, 95\% Cl 1.25 to 3.45 ) staff. Staff working in any clinical location were more likely to be seropositive (OR 2.68, 95\% 2.27 to 3.15 ). Staff were at an increased risk of seropositivity as the 'per 100 COVID-19 bed-days change' increased in the clinical area in which they worked (OR 1.12, 95\% 1.10 to 1.14). Staff working in critical care were no more likely to have detectable antibodies than staff working in non-clinical areas. Symptoms compatible with COVID-19 were reported in $41.8 \%$ and antibodies were detected in $30.7 \%$ of these individuals. In staff who reported no symptoms, antibodies were detected in $7.7 \%$. In all staff who had detectable antibodies, $25.2 \%$ reported no symptoms.

Conclusions Staff working in clinical areas where patients with COVID-19 were nursed were more likely to have detectable antibodies. The relationship between seropositivity in healthcare workers and the increase in 'per 100 COVID-19 bed-days' of the area in which they worked, although statistically significant, was weak, suggesting other contributing factors to the risk profile. Of staff with detectable antibodies and therefore evidence of prior infection, a quarter self-reported that they had experienced no compatible symptoms. This has implications for potential unrecorded transmission in both staff and patients.

\section{Strengths and limitations of this study}

- This is a large dataset of antibody results in healthcare staff who perform a broad range of roles in a large English teaching hospital.

- We have been able to compare seropositivity in clinical staff with the level of exposure to patients with COVID-19 by looking at patient movements.

- Small numbers of respondents in some clinical areas has prevented the ability to elucidate further which areas are genuine outliers that could indicate specific good practice or inadequacies leading to lower or higher staff infection rates.

- This study used a single antibody assay (Roche Elecsys) so all results in this study are comparable; however, other centres have used different assays, which means that comparison between sites is not straightforward.

- The Roche antibody assay is most sensitive after at least 21 days following infection and there is growing evidence of declining titres with time; therefore, false negative results could have been generated.

\section{INTRODUCTION}

SARS-CoV-2 has spread globally following its first identification in Wuhan, China in December $2019 .^{1-3}$ The WHO declared this to be a pandemic on 11 March $2020,{ }^{4}$ and to date ( 8 September 2020) there have been almost 27 million recorded cases and 900000 deaths globally. ${ }^{5}$ Cases were first identified in the UK on 31 January 2020 and to date (8 September 2020) there have been 350000 confirmed cases and over 41500 deaths. ${ }^{67}$

Studies have shown varying rates of infection in healthcare workers. These infections were determined as current, by detection of viral RNA by PCR, or as prior infection, by the detection of specific antibodies. National data from May 2020 shows increased rates of infection in patient-facing and resident-facing 
health/social care staff $(1.87 \%)$ compared with working people in other, non-healthcare associated roles $(0.32 \%)$. Analysis of registered deaths has shown that male healthcare workers had a higher death rate from COVID-19 compared with the general working population. ${ }^{9}$ Rates of infection detected in healthcare workers have varied geographically. Rates of 2\%-3\% asymptomatic infections have been described in some settings, ${ }^{10}{ }^{11}$ while higher rates were seen in a London Hospital, with a peak of $7.1 \%$, at the time that coincided with the peak in their local population. ${ }^{12}$ Houlihan and colleagues demonstrated rates of SARS CoV-2 infection of $44 \%$ in one cohort of patient-facing healthcare workers in London during a similar time period. ${ }^{13}$ Rates of $14 \%$ and $18 \%$ were described in symptomatic healthcare workers in March 2020, in Newcastle and Sheffield, respectively. ${ }^{15}$ A study of 554 healthcare workers in Birmingham showed that seroconversion had occurred in $24.4 \%$. Higher rates were seen in housekeeping $(34.5 \%)$, acute medicine $(33.3 \%)$, and general internal medicine $(30.3 \%)$. Lower rates were seen in critical care $(14.8 \%)$ and the emergency department (13.3\%). ${ }^{16}$ Oxford University Hospitals showed evidence of SARS-CoV-2 infection in $11 \%$ of their surveyed staff, also with higher rates seen in patient facing areas, including acute medicine. ${ }^{17}$

The emergence of this novel virus means that we have much to learn about its biology, host immunological response, and variable rates of infection. Additionally, there is a need to investigate the impact on the infection rate of the healthcare work force and the effectiveness of processes used to mitigate this. Here, we aimed to conduct a period prevalence study to ascertain the proportion of staff who had been infected with SARS-CoV-2.

\section{METHODS}

\section{Setting}

Lancashire Teaching Hospitals NHS Foundation Trust (LTH) is one of the largest acute Trusts in the UK, providing district general hospital services to 370000 people in Chorley, Preston and South Ribble and specialist care to 1.7 million people across Lancashire and South Cumbria. Approximately, 700 beds are spilt over two sites, Royal Preston Hospital and Chorley and South Ribble District Hospital. It employs circa 8500 staff, equating to circa 7600 full-time equivalents. In our Teaching Hospital setting the assessment, segregation and management of suspected COVID-19 patients were performed in alignment with Public Health England (PHE) guidance at the time. The trust was largely closed to elective admissions during this period and patients with COVID-19 were cared for throughout the trust. Patients were segregated on admission and placed in Green (COVID-19 not suspected), Amber (COVID-19 suspected but not confirmed) and Red (COVID-19 confirmed) areas. It was not possible to separate these areas into different wards; wards tended to have a mix of different types of patients, although separated into different bays, with bay doors closed. Isolation of all suspected cases in side-rooms was also not possible due to large numbers of admissions. Most suspected cases were nursed in Amber bays, pending the results of COVID-19 swabs and medical review. Throughout the first peak of the epidemic (March-July 2020), the hospital followed PHE guidance on the use of personal protective equipment (PPE).

\section{Participants}

We undertook a retrospective, anonymised analysis of SARS-CoV-2 antibody results in staff members at LTH between 29 May and 4 July 2020. All staff, regardless of role, were offered a serum antibody test for SARS-CoV-2 using the Roche Elecsys total immunoassay method (Roche Diagnostics, Burgess Hill, UK). The sensitivity and specificity were determined for the Roche Elecsys assay by an in house verification using 160 known positive RT-PCR patient samples and 199 prepandemic negative samples. Specificity was $100 \%$ and a maximum sensitivity of $92 \%$ was found to be at day 21. Additionally, both within and between batch precision was calculated using positive and negative patient samples. For all samples, the $\% \mathrm{CVs}$ were less than 5\%. All staff were required to give written consent for the test, which included continued agreement to adhere to local infection prevention and control policies regardless of the outcome of the test.

\section{Self-report survey}

Staff were additionally asked to self-report via a questionnaire whether they had previously tested positive for SARS-CoV-2 (by PCR), and whether they had experienced any compatible symptoms (online supplemental material 1). All staff who experienced compatible symptoms were excluded from work and offered a SARS-CoV-2 PCR. Staff with a confirmed diagnosis could return to work 10 days after the positive test if they were well. Staff who tested negative were permitted to return to work if they were well enough to do so. Self-reported PCR was used as some individuals may have accessed pillar two testing outside of the trust and these results would not be accessible. Location of work, and individual demographic data collected from the consent forms were cross-referenced with electronic staff records.

\section{Trust-wide COVID-19 data}

Information was retrieved from the Trust's Patient Administration System (PAS, QuadraMed, Texas, USA). This system logs every patient bed move with a date and a time. In mid-March, LTH introduced dashboards (Qlikview, Pennsylvania, USA) which combined COVID-19 test data with patient location data from the PAS. Bed movements of COVID-19 positive patients were analysed, including ward, and bed-space check-in and check-out dates and times. The dashboard included data on the first positive COVID-19 test performed in that visit; the date of sample collection and the date of the report. All inpatient beddays in the hospital visit after the first positive COVID-19 sample were included in the analysis and designated 
'COVID-19 positive inpatient bed-days'. These data were analysed to 8 July 2020 , which encompassed the first peak of incidence in our trust, and was used to assess varying exposure to patients with COVID-19 in different clinical areas.

There were 872 COVID-19 infected inpatients identified by PCR at LTH; 244 patients died; 610 patients were discharged home; 18 patients remained in hospital as of 8 July 2020. In total, these patients represented 9239 COVID-19 positive inpatient bed days. A total of 42 clinical locations were identified and the number of COVID-beds days were estimated for each location. These locations included clinical areas with no patients with COVID-19, such as the entire Women's and Children's Division. Other workplaces such as offices, pathology and pharmacy were designated as a single non-clinical location with no patients with COVID-19.

\section{Statistical analysis}

Summary statistics were used for descriptive analyses. Sensitivity and specificity were calculated with the standard formulae. The primary modelling framework was binary logistic regression for which the outcome was a positive or negative antibody test. The demographic predictors in the logistic regression were age (as a quantitative covariate), gender and ethnicity. Ethnicity was categorised into six ethnic groups and a seventh group which comprised all respondents for whom ethnicity was unknown. This approach allowed only those of known ethnicity to contribute to the estimates for their ethnic group but allowed all respondents to contribute to estimates for age, gender and environmental location. Location was initially categorised into two types; non-clinical and clinical locations. Location was also classified into 43 separate locations, the first being all non-clinical locations combined and the remainder being 42 different clinical locations. Each of the clinical locations was ascribed an estimated number of COVID-19 bed-days as described above. Finally, location was classified into four main types comprising all non-clinical locations, emergency department, critical care and all remaining clinical locations combined. Logistic regressions that included individual locations were restricted to those locations with at least 30 participants to avoid large confidence intervals and over-parameterisation.

Logistic regression models prevalence using a linear model for the logarithm of the odds where odds are defined as the ratio of the positive outcomes to the negative outcomes. Results are presented as ORs where the OR measures the extent to which one group has a different risk of the positive outcome relative to a reference group. Thus, an OR of 2.0 implies that this group has twice the odds of a positive outcome compared with the reference group. The reference group thus always has an OR of 1.0. Higher risk groups have an OR greater than 1.0 and lower risk groups have an OR of less than 1.0. The reference groups in this study were male gender, white UK or ROI ethnicity and zero COVID-19 bed days. The modelling approach allows locations to be compared for prevalence after adjustment has been made for demographic differences between different locations. Statistical analyses were performed using IBM SPSS.

\section{Patient and public involvement}

Patients or the public were not involved in the design, or conduct, or reporting, or dissemination plans of our research. Results will be made available to all staff and patients via our usual communication channels.

\section{RESULTS}

\section{Summary statistics}

Staff with incomplete data $(37 / 4511)$ were excluded in the data analysis stage. These staff were excluded because age and gender were not known, the antibody test result was invalid, or there was a major inconsistency in the demographic data. This resulted in 4474 individuals being included in all analyses except where individual location ORs were estimated. In this case, exclusion of locations with fewer than 30 participants resulted in 4189 individuals included. Staff who presented for antibody testing were representative of Trust staff in regard to age, sex, ethnicity and staff type when compared with workforce staff records (data not shown) and hence results presented are unlikely to contain any inherent bias. Antibodies were detected in 777 (17.4\%) individuals (table 1).

\section{Demographic characteristics}

Older staff were less likely to be seropositive (OR 0.988, $95 \%$ CI 0.982 to $0.994, \mathrm{p}<0.001)$ per 1 year change (table 2). Staff who were Asian/Asian British (OR 1.61, 95\% CI 1.27 to 2.04) and black/black British (OR 2.08, $95 \%$ CI 1.25 to 3.50 ) were more likely to have detectable antibodies than staff of white UK/ROI ethnicity when corrected for age, gender and clinical location (table 2).

\section{Locations}

Staff working in any clinical location where patients with COVID-19 were nursed were more likely to be seropositive (OR 2.68, 95\% 2.27 to 3.15) when corrected for age, sex and ethnicity (table 2). There was a positive association of staff seropositivity per 100 COVID-19 bed-day increase in the clinical area in which they worked (OR 1.12, 95\% 1.10 to $1.14, \mathrm{p}<0.001)$. The relationship between COVID-19 bed days and staff seropositivity was significant, but weak. The superimposed trend line through the logarithm of the odds ratios (treated as single points) illustrates the substantial non-conformity with a linear relationship with COVID-19 bed-days (figure 1). Staff working in either the emergency department or in critical care were no more likely to have detectable antibodies than staff working in non-clinical areas (table 3). Patients with COVID-19 were cared for throughout the trust and the 'COVID-19 bed days' demonstrates the range of potential staff exposure across medical and surgical wards. Of note however, the increased risk of seroconversion of staff working in the 


\begin{tabular}{|c|c|c|}
\hline \multicolumn{3}{|l|}{$\begin{array}{l}\text { Demographic } \\
\text { characteristics }\end{array}$} \\
\hline Gender: n (\%) & Male & 980 (21.9) \\
\hline Age: mean (SD) & Years & 42.5 (13.2) \\
\hline \multirow[t]{7}{*}{ Ethnicity: n (\%) } & Asian/Asian British & $492(11.0)$ \\
\hline & Black/black British & $79(1.8)$ \\
\hline & Chinese & $21(0.5)$ \\
\hline & Mixed & $66(1.5)$ \\
\hline & White UK and ROI & $3143(70.3)$ \\
\hline & White other & $123(2.7)$ \\
\hline & Unknown & 550 (12.3) \\
\hline \multicolumn{3}{|l|}{$\begin{array}{l}\text { Environmental } \\
\text { characteristics }\end{array}$} \\
\hline \multirow[t]{4}{*}{ Locations: n (\%) } & Non-clinical & $2728(61.0)$ \\
\hline & Emergency department & 305 (6.8) \\
\hline & Critical care & $209(4.7)$ \\
\hline & Other clinical locations & $1232(27.5)$ \\
\hline \multicolumn{3}{|l|}{$\begin{array}{l}\text { Clinical } \\
\text { characteristics }\end{array}$} \\
\hline \multirow[t]{5}{*}{ PCR result: n (\%) } & Positive & $209(4.7)$ \\
\hline & Negative & $541(12.1)$ \\
\hline & Not performed & $3698(82.7)$ \\
\hline & Inconclusive & $16(0.4)$ \\
\hline & Unknown & $10(0.2)$ \\
\hline \multirow[t]{3}{*}{ Symptoms: n (\%) } & Yes & $1871(41.8)$ \\
\hline & No & $2547(56.9)$ \\
\hline & Unknown & $56(1.3)$ \\
\hline \multirow[t]{2}{*}{ Antibody result: n (\%) } & Positive & 777 (17.4) \\
\hline & Negative & 3697 (82.6) \\
\hline
\end{tabular}

emergency department only just failed to reach significance (OR 1.38, $95 \% 0.98$ to 1.93 , $\mathrm{p}=0.062$ ). One medical ward demonstrated the largest positive trend to staff seropositivity (OR $15.36,95 \%$ CI 7.21 to 32.74 ); however, the relatively small number of responders generated a wide CI (table 3).

\section{Prevalence and symptoms}

Most staff responded to the question regarding whether they had experienced symptoms compatible with COVID-19 (4418/4474). Of these responders, $41.8 \%$ $(1871 / 4474)$ reported symptoms. Antibodies were detected in 574/1871 (30.7\%) individuals who reported symptoms, and 196/2547 (7.7\%) individuals who reported no symptoms (table 4). Of those with antibodies detected, 25.2\% (196/777) reported no symptoms. Sensitivity and specificity of self-reported symptoms as an indication of COVID-19 infection were $74.5 \%$ (95\% CI $71.3 \%$ to $77.6 \%$ ) and $64.5 \%$ (95\% CI $62.9 \%$ to $66.0 \%$ ), respectively.
Table 2 OR from the binary logistic regression for demographic characteristics and location type $(n=4474)$

\begin{tabular}{|c|c|c|c|}
\hline & OR & $95 \% \mathrm{Cl}$ & $P$ value \\
\hline $\begin{array}{l}\text { Age per } 1 \text { year } \\
\text { change }\end{array}$ & 0.988 & 0.982 to 0.994 & $<0.001$ \\
\hline $\begin{array}{l}\text { Male (reference } \\
\text { category) }\end{array}$ & 1.000 & & \\
\hline Female & 1.060 & 0.868 to 1.293 & 0.568 \\
\hline $\begin{array}{l}\text { White UK and ROI } \\
\text { (reference category) }\end{array}$ & 1.000 & & \\
\hline Asian/Asian British & 1.608 & 1.266 to 2.042 & $<0.001$ \\
\hline White other & 1.275 & 0.792 to 2.051 & 0.317 \\
\hline Black/black British & 2.080 & 1.254 to 3.449 & 0.005 \\
\hline Mixed & 0.722 & 0.351 to 1.487 & 0.377 \\
\hline Chinese & 0.619 & 0.179 to 2.145 & 0.449 \\
\hline Unknown ethnicity & 1.441 & 1.140 to 1.823 & 0.002 \\
\hline $\begin{array}{l}\text { Non-clinical location } \\
\text { (reference category) }\end{array}$ & 1.000 & & \\
\hline Clinical location & 2.675 & 2.268 to 3.154 & $<0.001$ \\
\hline
\end{tabular}

Testing for SARS-CoV-2 by PCR was reported by 772 individuals. A valid result was recorded or available for 746 of these staff members (staff who recorded that they were not informed of their result, and invalid results were excluded). A small number of staff $(n=5)$ self-reported a positive SARS-CoV-2 PCR but tested antibody negative. Antibodies were detected in 79 members of staff who selfreported a negative PCR.

\section{DISCUSSION}

We report a large dataset of SARS-CoV-2 antibody results for staff performing various roles in a large teaching hospital. We are not aware of any other published dataset of comparable size, nor of any that have used this Roche antibody assay in healthcare workers. Our finding of $17.4 \%$ seroprevalence in our staff compares to a range of $7 \%-44 \%$ in other studies. ${ }^{12-17}$ Differences in the number of staff infections have varied geographically. This is likely to be multifactorial and the number of infections in the local community is likely to contribute. By the end of this study period (early July 2020), it was estimated that seroprevalence in the North West of England as a whole was approximately $8 \% .{ }^{18}$ It is also noteworthy that numerous antibody assays are being used nationally and their different performance characteristics may contribute to these differences. Our findings that staff working in most clinical areas are more likely to have been infected with SARS-CoV-2 than non-clinical staff are concordant with other studies. Likewise, the finding that lower rates of infection in staff working in the emergency or critical care departments demonstrated in this study has been noted previously. ${ }^{16}$ Higher rates of infection in black and ethnic minority individuals have also been reported nationally. ${ }^{19}$ 


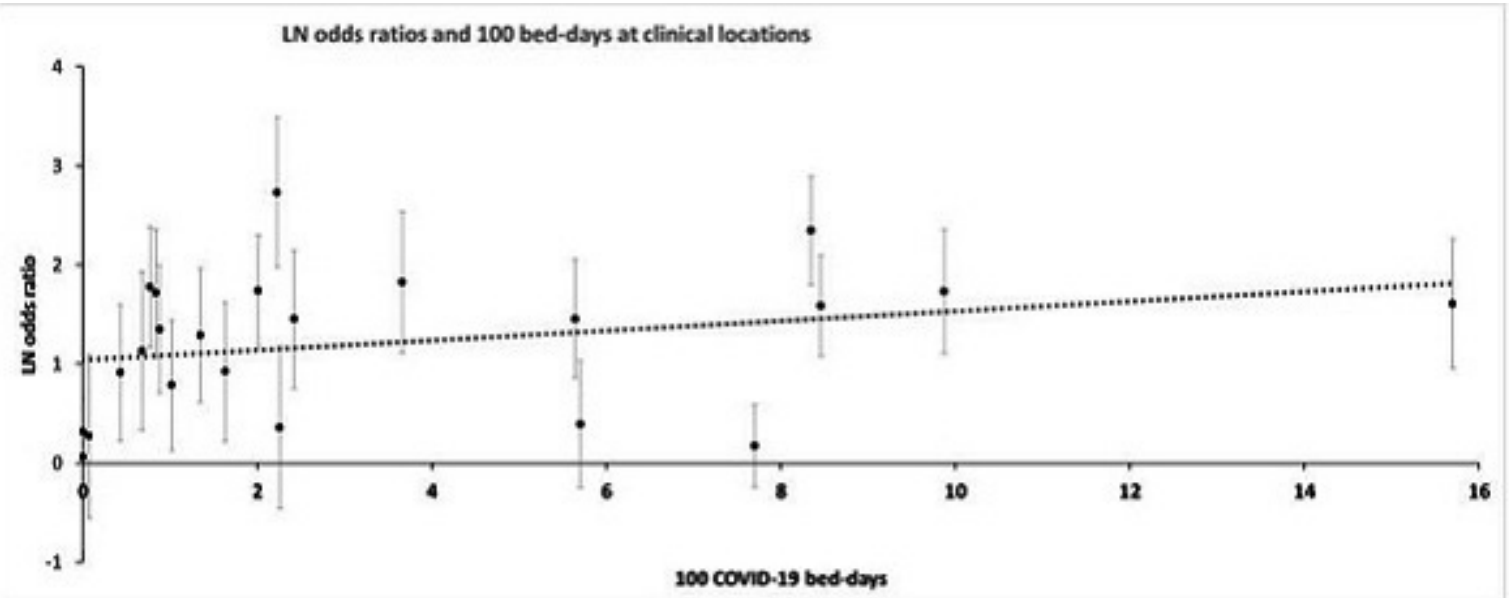

Figure 1 ORs for individual clinical locations relative to a non-clinical location against COVID-19 bed-days at each location; points are ORs, bars are $95 \% \mathrm{Cls}$ and dashed line illustrates the trend through ORs treated as points.

Table 3 COVID-19 bed-days and OR for seropositivity from the binary logistic regression for demographic characteristics and the 24 different locations with 30 or more respondents $(n=4189)$; only ORs for locations shown

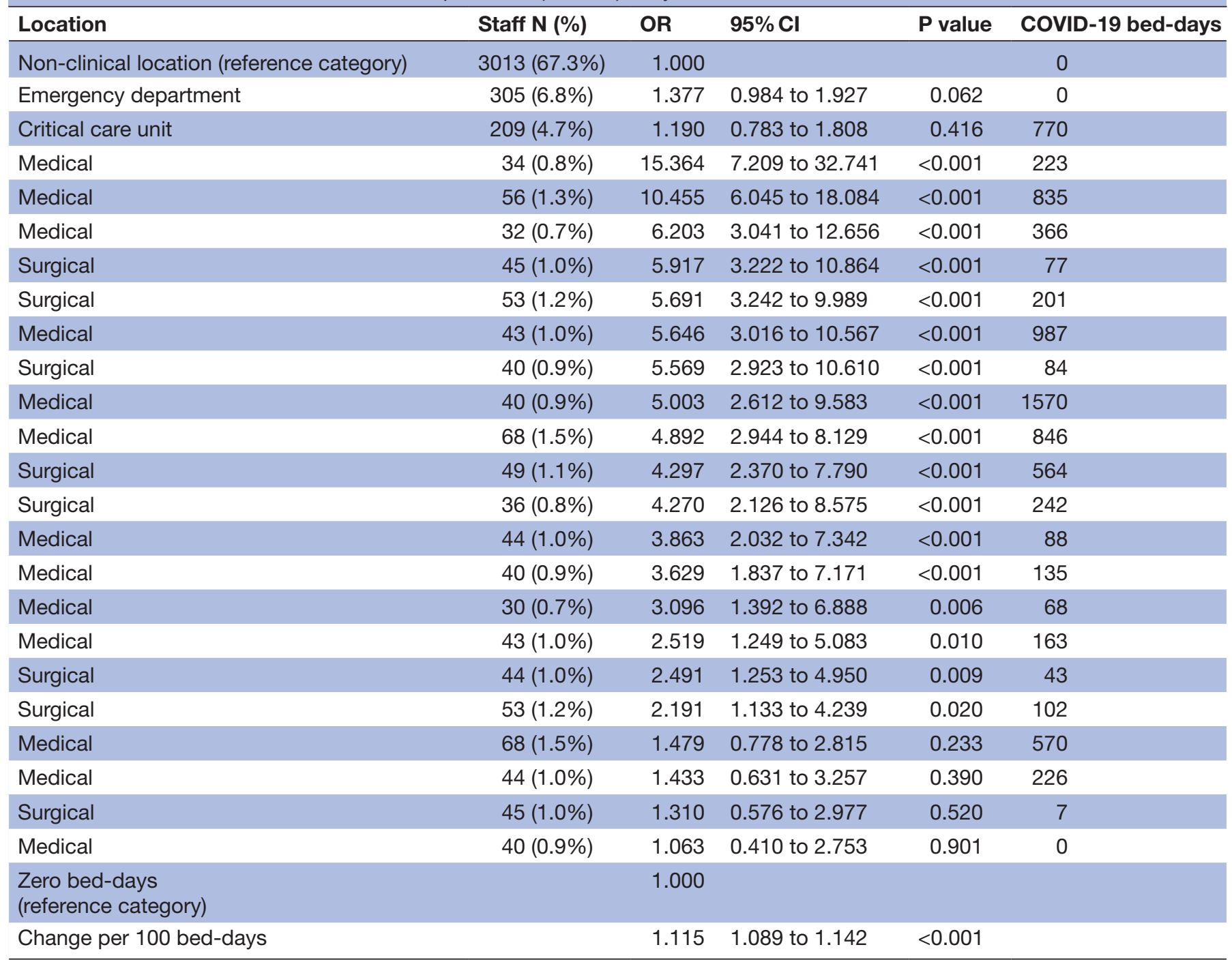

OR for 100 bed-days change also shown $(n=4474)$. 
Table 4 Symptoms and COVID-19 antibody prevalence

Respondents' self-report:

\section{Symptomatic $(n=1871) \quad$ Asymptomatic $(n=2547) \quad(n=56)$}

\begin{tabular}{|llccc}
\hline Antibody test negative: & PCR result: & & & \\
& Negative & 375 & 0 & 2 \\
& Positive & 5 & 2261 & 0 \\
& Not performed & 906 & 3 & 47 \\
& Inconclusive & 7 & 2 & 0 \\
& Unknown & 4 & $(92.3 \%) 2351$ & 0 \\
\hline & Total & $(69.3 \%) 1297$ & & 49 \\
Antibody test positive: & PCR result: & & 6 & 0 \\
& Negative & 73 & 3 & 2 \\
& Positive & 199 & 186 & 5 \\
& Not performed & 293 & 0 & 0 \\
& Inconclusive & 6 & 1 & 0 \\
& Unknown & 3 & $(7.7 \%) 196$ & 7
\end{tabular}

The finding that the number of COVID-19 bed-days of a clinical area correlates with the prevalence of staff seropositivity is intuitive. However, this weak association suggests that factors other than the number of patients with COVID-19 in a clinical area contribute to the risk of staff infection. These could be numerous, and not limited to: adequacy and compliance with PPE, relative ventilation and air changes per hour, social distancing of staff groups within the clinical and recreational areas, and inappropriate de-escalation of patients with COVID-19 based on false-negative PCR results. This latter risk was somewhat mitigated by the introduction of fluid-resistant surgical masks in all patient-facing healthcare workers from early April. It was not possible to ascertain why some clinical areas have higher numbers of staff seroconversion than others. This is likely to be multifactorial and would require further investigation. The finding that a quarter of staff with antibodies reported no compatible symptoms indicates that asymptomatic infection occurred at significant levels and has implications for the control of this pandemic. It should be considered that onward transmission from such individuals may be possible if compliance with guidance regarding PPE and distancing is not followed.

Of the staff $(2 / 5)$ whose positive PCR was performed at our trust, the PCR result preceded the antibody test by at least 21 days, allowing sufficient time to produce antibodies. These discrepancies could be a result of a false-positive PCR result, a false-negative antibody result, or a genuine case of no immune response being elicited. Likewise, it was not possible to definitively determine why some staff had demonstrable antibodies and a negative PCR result. This may be due to a myriad of reasons, including the timing or quality of the swab sampling, or that the symptoms that prompted testing were due to another cause and individuals were previously, or subsequently, asymptomatically infected with SARS-CoV-2.

This retrospective analysis has some limitations. First, although comparison with trust electronic staff records shows that our respondents are representative of the trust as a whole, there is a potential for ascertainment bias with staff who knew or believed that they were infected to be more likely to come forward for testing. The varying numbers of individuals in different clinical areas have generated wide confidence intervals. This reduces the ability to elucidate further which areas are genuine outliers that could indicate specific good practice or inadequacies leading to lower or higher staff infection rates. This study used a single antibody assay so all results in this study are comparable. However, other centres have used different assays, which means comparison of rates of staff infection between sites is not straightforward. Furthermore, the Roche antibody assay is most sensitive after at least 21 days following infection and there is growing evidence of declining titres with time. It is therefore possible that false negative results could be generated as a result of sampling staff prior to 21 days after infection, or due to waning antibody titres if infection occurred far earlier in the pandemic.

This COVID-19 pandemic has necessitated new ways of working and has led to innovation in healthcare systems. As the clinical presentation and progression have been more clearly characterised, along with a greater understanding of the diagnostic tools available, case finding (especially nosocomial infection) has improved. This should reduce the frequency in which infected patients are inappropriately de-escalated to non-COVID-19 areas, and therefore reduce further transmission, including to 
staff. Our data clearly show that staff who work in clinical areas with large numbers of COVID-19 patients are more likely to have demonstrable SARS CoV-2 infection. However, this is not the only correlating factor. Using these data to further reduce the risk to healthcare workers in all settings must be a priority. Real-time data to show particular hotspots with high numbers of COVID-19 bed-days could prompt proactive staff surveillance, with enhanced audit of infection prevention and control practice in areas with suspected high rates of transmission.

\section{Author affiliations}

${ }^{1}$ Department of Microbiology, Lancashire Teaching Hospitals NHS Foundation Trust, Preston, UK

${ }^{2}$ Centre for Clinical Microbiology, University College London, London, UK

${ }^{3}$ Department of Clinical Biochemistry, Lancashire Teaching Hospitals NHS Foundation Trust, Preston, UK

${ }^{4}$ Research Support Team, University of Central Lancashire, Preston, UK

${ }^{5}$ Department of Immunology, Lancashire Teaching Hospitals NHS Foundation Trust, Preston, UK

\section{Twitter Robert John Shorten @robshorten}

Acknowledgements Chris Baron, deputy head of transformation \& business, Lancashire Teaching Hospitals NHS Foundation Trust for data support.

Contributors RJS and SH contributed equally to this research and should be acknowledged as such in the list of authors. All authors were involved in the conceptual design of this study. SH, MM and PW established the antibody test. PW established the PCR test. DO led the Trust's COVID-19 response and established the 'COVID bed days' dashboard. RJS and SH wrote the manuscript and analysed the initial data. MAH provided statistical analysis and advice. All authors were involved in manuscript review.

Funding The authors have not declared a specific grant for this research from any funding agency in the public, commercial or not-for-profit sectors.

Competing interests None declared.

Patient consent for publication Not required.

Ethics approval HRA and Health and Care Research Wales approval was granted for this study (REC reference 20/HRA/3858).

Provenance and peer review Not commissioned; externally peer reviewed.

Data availability statement Data are available upon reasonable request. Deidentified data are available from the corresponding author upon reasonable request.

Supplemental material This content has been supplied by the author(s). It has not been vetted by BMJ Publishing Group Limited (BMJ) and may not have been peer-reviewed. Any opinions or recommendations discussed are solely those of the author(s) and are not endorsed by BMJ. BMJ disclaims all liability and responsibility arising from any reliance placed on the content. Where the content includes any translated material, BMJ does not warrant the accuracy and reliability of the translations (including but not limited to local regulations, clinical guidelines, terminology, drug names and drug dosages), and is not responsible for any error and/or omissions arising from translation and adaptation or otherwise.

Open access This is an open access article distributed in accordance with the Creative Commons Attribution Non Commercial (CC BY-NC 4.0) license, which permits others to distribute, remix, adapt, build upon this work non-commercially, and license their derivative works on different terms, provided the original work is properly cited, appropriate credit is given, any changes made indicated, and the use is non-commercial. See: http://creativecommons.org/licenses/by-nc/4.0/.
ORCID iD

Robert John Shorten http://orcid.org/0000-0001-6894-9325

\section{REFERENCES}

$1 \mathrm{Lu} \mathrm{H}$, Stratton CW, Tang Y-W. Outbreak of pneumonia of unknown etiology in Wuhan, China: the mystery and the miracle. J Med Virol 2020;92:401-2.

2 Huang C, Wang Y, Li X, et al. Clinical features of patients infected with 2019 novel coronavirus in Wuhan, China. Lancet 2020;395:497-506.

3 Zhu N, Zhang D, Wang W, et al. A novel coronavirus from patients with pneumonia in China, 2019. N Engl J Med 2020;382:727-33.

4 World Health Organization,. Coronavirus disease (COVID-2019) situation reports [Internet] - [cited 08/09/2020]. Available: https:// www.who.int/docs/default-source/coronaviruse/situation-reports/ 20200311-sitrep-51-covid-19.pdf?sfvrsn=1ba62e57_10

5 World Health Organization. Coronavirus disease (COVID-2019) situation reports [Internet]. [Cited 08/09/2020]. Available: https:// www.who.int/docs/default-source/coronaviruse/situation-reports/ 20200907-weekly-epi-update-4.pdf?sfvrsn=f5f607ee_2

6 Docherty AB, Harrison EM, Green CA, et al. Features of 20133 UK patients in hospital with covid-19 using the ISARIC WHO Clinical Characterisation Protocol: prospective observational cohort study. BMJ 2020;369:m1985.

7 Gov.UK COVID-19 Dashboard [Internet]. [Cited 08/09/2020]. Available: https://coronavirus.data.gov.uk/

8 Office of National Statistics. Coronavirus (COVID-19) Infection Survey pilot: 5 June 2020. London: ONS, 2020 [Internet]. [Cited 08/09/2020]. Available: https://www.ons.gov.uk/peoplepopulationandcommunity/ healthandsocialcare/conditionsanddiseases/bulletins/coronavirusc ovid19infectionsurveypilot/5june2020

9 Office of National Statistics. Coronavirus (COVID-19) related deaths by occupation, England and Wales: deaths registered up to and including 20 April 2020. London: ONS, 2020 [Internet]. [Cited 08/09/2020]. Available: https://www.ons.gov.uk/peoplepopulation andcommunity/healthandsocialcare/causesofdeath/bulletins/coro naviruscovid19relateddeathsbyoccupationenglandandwales/deat hsregistereduptoandincluding20april2020

10 Rivett L, Sridhar S, Sparkes D, et al. Screening of healthcare workers for SARS-CoV-2 highlights the role of asymptomatic carriage in COVID-19 transmission. Elife 2020;9:e58728.

11 Brown CS, Clare K, Chand M, et al. Snapshot PCR surveillance for SARS-CoV-2 in hospital staff in England. J Infect 2020;81:427-34.

12 Treibel TA, Manisty C, Burton M, et al. COVID-19: PCR screening of asymptomatic health-care workers at London Hospital. Lancet 2020;395:1608-10.

13 Houlihan CF, Vora N, Byrne T, et al. Pandemic peak SARS-CoV-2 infection and seroconversion rates in London frontline health-care workers. Lancet 2020;396:e6-7.

14 Hunter E, Price DA, Murphy E, et al. First experience of COVID-19 screening of health-care workers in England. Lancet 2020;395:e77-8.

15 Keeley AJ, Evans C, Colton $\mathrm{H}$, et al. Roll-Out of SARS-CoV-2 testing for healthcare workers at a large NHS Foundation trust in the United Kingdom, March 2020. Euro Surveill 2020;25:2000433.

16 Shields AM, Faustini SE, Perez-Toledo M. SARS-CoV-2 seroconversion in health care workers. Thorax.

17 Eyre DW, Lumley SF, O’Donnell D, et al. Differential occupational risks to healthcare workers from SARS-CoV-2 observed during a prospective observational study. Elife 2020;9:e60675.

18 Public Health England. Weekly Coronavirus Disease 2019 (COVID-19) surveillance report Summary of COVID-19 surveillance systems [Internet]. [Cited 13/11/2020]. Available: https://assets.publishing. service.gov.uk/government/uploads/system/uploads/attachment data/file/920372/Weekly_COVID19_Surveillance_Report_week_37_ FINAL_UPDATED.pdf

19 Ward $\bar{H}$, Atchison WM, Ainslie KEC. Antibody prevalence for SARSCoV-2 following the peak of the pandemic in England: REACT2 study in 100,000 adults. medRxiv. 